\title{
Auditory abnormalities in children with autism
}

\author{
Ying-Hua Tan, Chun-Yan Xi*, Shu-Ping Jiang, Bing-Xin Shi, Li-Bo Wang, Lin Wang
}

Developmental Pediatrics of Shengjing Hospital, China Medical University, Shenyang, China

Email: *xichy2006@yahoo.com.cn

Received 27 October 2011; revised 31 November 2011; accepted 11 December 2011

\begin{abstract}
The present study aimed to describe the characteristics of auditory abnormalities present in cases of autism. One hundred and fifty six children with autism and 141 matched controls with language delay were investigated via direct observations combined with parent/caregiver reports. All of the autistic individuals demonstrated auditory abnormalities especially in the domain of hyposensitivity, compared with $33.3 \%$ of children with language delay. The auditory abnormalities in autism primarily comprised of auditory hyposensitivity, auditory hypersensitivity, phonophobia, and peculiar interests in certain sounds. Participants with autism were rated as having more problems than the language-delayed children in all the items of each domain. No significant differences in the range of auditory abnormalities were observed between mild and severe autistic children except for the presence of phonophobia. Children with autism presented with diverse auditory abnormalities which may be specific features in autism and may play an important role in the early identification of autism.
\end{abstract}

Keywords: Autism; Auditory Abnormalities; Auditory Profile

\section{INTRODUCTION}

Autism is a pervasive developmental disorder characterized by symptoms in three core domains: qualitative impairments in social interaction, verbal and nonverbal communication, and stereotyped patterns of activities and interests [1,2]. The prevalence of autism has evidenced a rapid increase over the last few years, now amounting to as many as 10 to 30 per 10,000 children. Males are more often affected with autism, at a ratio of 4:1 (males:females) [3].

In addition to the core features, it has been reported that children with autism manifested varied unusual responses to sensory stimuli [4-8]. Rogers et al. using parent questionnaires found that toddlers with autism had

${ }^{*}$ Corresponding author. more deficits in tactile sensitivity, auditory filtering, and taste/smell sensitivity as measured by the Short Sensory Profile [9] than those with other developmental delays [5]. It was also described that children with autism showed a preference for proximal stimuli including touch, smell and taste as opposed to the distal aspects such as auditory and vision $[10,11]$. Abnormal sensory behaviors have been recently proposed for inclusion among diagnostic criteria for autism spectrum disorder in the upcoming Diagnostic and Statistical Manual of Mental Disorder, version 5 (DSM-V) [12,13]. Auditory abnormalities tend to be particularly evident among all the modalities including not only hyposensitivity to auditory stimuli but also hyperacusia $[12,14,15]$. Data derived from children with autism spectrum disorder showed that these children had more problems in responding to voice or their names being called than the developmental delay group [6]. The authors suggested that such abnormalities might be distinguishing symptoms of autism (spectrum disorders) that should be considered for inclusion in diag- nostic algorithms for young children.

Although major advances have been made in understanding and identifying the core symptoms in children with autism over the past two decades, research characterizing the auditory profiles of children with autism remains limited. The literature regarding auditory abnormalities in people with autism mainly revolved around the electrophysiological and neuroimaging aspects, including auditory brainstem response, otoacoustic emission, immittance audiometry, and event-related potentials [1621]. The purpose of this study was to investigate the features of auditory abnormalities in autism and to compare differences in the auditory profiles of children with autism, matched to a control group of children with developmental language delay to determine whether children with autism exhibit a unique profile of auditory response.

\section{MATERIALS AND METHODS}

\subsection{Participants}

One hundred and fifty six children with autism aged 1.9 5.8 years (142 boys and 14 girls, mean age $=3.5$ years) and 141 children with developmental language delay aged 
2.0 - 5.5 years $(125$ boys and 16 girls, mean age $=3.2$ years) were investigated. The two groups were approximately matched by age and gender. Participants were recruited from the Clinic of Developmental Pediatrics of Shengjing Hospital of China Medical University. They were all ethnic Chinese. The study was approved by the Ethical Committee of Shengjing Hospital of China Medical University.

Participants were diagnosed by a team of experienced developmental pediatricians. All children in the experimental group fulfilled the DSM-IV criteria for autism [1]. Children with developmental language delay were included if they failed to express words by 24 months or phrases by 3 years of age. We used Childhood Autism Rating Scale (CARS, Chinese Version) [22] to evaluate all the children. We also used the CARS to assess the the presentation of symptoms of autism. According to CARS, children who scored 30 - 36 points indicated mild to moderate autism $(\mathrm{n}=92)$, and those whose scores ranged from 37 to 60 points manifested severe autism $(n=64)$. Exclusion criteria for both groups were the presence of hearing impairment, chromosomal abnormalities (e.g. Fragile x syndrome) or neurological disorders (e.g. epilepsy, seizure disorders). Whether a child had hearing impairment or not was determined by the auditory brainstem response. Those who did not complete all the evaluations were excluded as well. Informed consents were obtained from the caregivers of the subjects.

\subsection{Measures}

The auditory characteristics of participants were evaluated by direct observations combined with parent reports. The child's caregiver was present during the evaluation. The assessment was carried out individually and was a face-to-face evaluation of the child interacting with a parent and a clinician in a quiet room with the same set- ting. The rater as well as the parents/primary caregivers did not know the final clinical diagnosis of the children at the time of data collection. The process entailed two steps: (a) the researchers were divided into two pairs to ensure that each assessment was reviewed by at least two evaluators with each evaluator categorizing items independently; and (b) evaluators compared results and resolved any disagreements via a consensus across evaluators.

We formulated a checklist based on previous studies $[5,6,11,23]$. The auditory abnormalities were coded within the following four domains: auditory hyposensitivity, auditory hypersensitivity, phonophobia, and peculiar interests in certain sounds.

\subsection{Statistical Analysis}

Statistical analysis was carried out using SPSS (version 13.0, SPSS, Chicago, IL, USA). Analysis of frequency was performed. A chi-squared $\left(\chi^{2}\right)$ test was used for comparisons between groups. All reported $P$ values were two-tailed. A $p$ value of $<0.05$ was considered significant.

\section{RESULTS}

Children with autism were reported to show more auditory abnormalities than participants diagnosed with language delay. Significant differences were observed in each domain between groups. To further explore the contrasting auditory profiles between groups, $\chi^{2}$ tests were also used on each auditory abnormality item. Children with autism displayed significantly more problems than language-delayed children in each item, especially in those items of auditory hyposensitivity, peculiar interests in certain sounds, as well as that of "oversensitive to the name of foods", "over-distressed by some high-pitch voice" and "discomfort with ordinary talking" (see Table 1).

Table 1. Comparison of auditory abnormalities between groups with autism and language delay.

\begin{tabular}{|c|c|c|c|c|}
\hline \multirow{2}{*}{ Auditory abnormalities } & \multirow{2}{*}{$\begin{array}{c}\text { Autism } \\
\mathrm{n}=156 \\
\mathrm{n}(\%)\end{array}$} & \multirow{2}{*}{$\begin{array}{c}\text { Language delay } \\
n=141 \\
n(\%)\end{array}$} & \multicolumn{2}{|c|}{ Group comparisons } \\
\hline & & & $\chi^{2}$ & $p$ \\
\hline Total & $156(100 \%)$ & $47(33.3 \%)$ & 152.16 & $<0.001$ \\
\hline Auditory hyposensitivity & $107(68.6 \%)$ & $14(9.9 \%)$ & 105.56 & $<0.001$ \\
\hline 1.Ignoring when name called & $99(63.5 \%)$ & $10(7.1 \%)$ & 101.29 & $<0.001$ \\
\hline 2.Responds negatively to unexpected/loud sounds & $56(35.9 \%)$ & $5(3.5 \%)$ & 47.49 & $<0.001$ \\
\hline Auditory hypersensitivity & 77 (49.4\%) & $40(28.4 \%)$ & 13.67 & $<0.001$ \\
\hline 1.Oversensitive to music & 59 (37.8\%) & $37(26.2 \%)$ & 4.54 & 0.033 \\
\hline 2.Oversensitive to the name of foods & $39(25.0 \%)$ & $9(6.4 \%)$ & 18.94 & $<0.001$ \\
\hline Phonophobia & $55(35.3 \%)$ & $8(5.7 \%)$ & 38.78 & $<0.001$ \\
\hline 1.Over-distressed by some high-pitch voices & $32(20.5 \%)$ & $5(3.5 \%)$ & 19.55 & $<0.001$ \\
\hline 2.Feels uncomfortable with usual sound of talking & $19(12.2 \%)$ & $1(0.7 \%)$ & 15.51 & $<0.001$ \\
\hline 3.Afraid of the sound of car motors or hooters & $15(9.6 \%)$ & $3(2.1 \%)$ & 7.29 & 0.007 \\
\hline 4.Fears the sound of talking toys & $12(7.7 \%)$ & $2(1.4 \%)$ & 6.49 & 0.011 \\
\hline Peculiar interests in certain sounds & 57 (36.5\%) & $7(5.0 \%)$ & 43.67 & $<0.001$ \\
\hline 1.Fascinates with the sound of knocking the tables & $27(17.3 \%)$ & $0(0 \%)$ & 26.84 & $<0.001$ \\
\hline 2.Indulges in the sound that produced by shaking a bottle or box & $30(19.2 \%)$ & $0(0 \%)$ & 30.16 & $<0.001$ \\
\hline $\begin{array}{l}\text { 3.Unusual acute hearing of some television program } \\
\text { (e.g., weather forecast or news broadcast) }\end{array}$ & $29(18.6 \%)$ & $7(5.0 \%)$ & 12.91 & $<0.001$ \\
\hline
\end{tabular}


No group difference was found between mild to moderate autism and severe autism in the auditory abnormalities except for the item relating to phonophobia (see Table 2).

\section{DISCUSSION}

Although investigation of auditory abnormalities in autism is by no means a novel topic, few studies have systematically characterized the auditory profiles of children with autism. In the present study, we investigated the auditory behavior features in a relatively large sample of autistic children by comparing with children with developmental language delay, to examine the auditory profiles of children with autism.

\subsection{Rate of Auditory Abnormalities}

The prevalence of auditory abnormalities in autism has been reported to be ranging from $16 \%$ to $100 \%$ [10]. Participants with autism in this sample manifested a significantly higher rate of auditory abnormalities than children with developmental language delay. All the children with autism presented varied auditory abnormalities, compared with only $33.3 \%$ of language delayed children. These results, combined with previous reports, suggest that auditory abnormalities may be a common feature of autism $[5,6]$.

A diagnosis of autism is primarily based on the three core features identified during early infancy. There is however difficulty in identifying suspected cases through early communication problems given the developing abilities in infancy. In our study, we found that the parents/ caregivers of autistic children often reported auditory abnormalities present earlier than other markers of impairments. This may suggest that the auditory abnormalities distinguish the children with autism from language delay even in early months of life.

\subsection{Auditory Hyposensitivity and Auditory Hypersensitivity}

The abnormal auditory sensitivity in autism mainly ma-

Table 2. Comparing of the auditory abnormalities in mild to moderate autism and severe autism.

\begin{tabular}{cccccc}
\hline \multirow{2}{*}{$\begin{array}{c}\text { Auditory abnormalities } \\
\text { domain }\end{array}$} & $\begin{array}{c}\text { Mild to moderate } \\
\text { autism }\end{array}$ & $\begin{array}{c}\text { Severe } \\
\text { autism }\end{array}$ & \multicolumn{2}{c}{$\begin{array}{c}\text { Group } \\
\text { comparisons }\end{array}$} \\
\cline { 2 - 4 } & $\mathrm{n}=92$ & $\mathrm{n}=64$ & $\chi^{2}$ & $P$ \\
\cline { 2 - 4 } Auditory hyposensitivity & $60(65.2 \%)$ & $47(73.4 \%)$ & 1.18 & 0.277 \\
Auditory hypersensitivity & $50(54.3 \%)$ & $27(42.2 \%)$ & 2.33 & 0.135 \\
$\begin{array}{c}\text { Phonophobia } \\
\begin{array}{c}\text { Peculiar interests in } \\
\text { certain sounds }\end{array}\end{array}$ & $237(25.0 \%)$ & $32(50.0 \%)$ & 10.33 & 0.001 \\
\hline
\end{tabular}

nifested as auditory hyposensitivity and auditory hypersensitivity. Indications of hyposensitivity were most frequent among all the auditory abnormalities. Children with autism were often unresponsive to meaningful speech, e.g. ignoring when name called and responding negatively to unexpected/loud noise, therefore, many participants were initially thought to be hearing impaired. In addition, some individual with autism may respond only to their parents or caregivers. These selective responses were reported in 41 (26.3\%) autistic children, but none of the language delay group. Conversely, many participants with autism demonstrated oversensitivity to certain sounds, even at low volume e.g. the name of foods or their favorite things. Although both children with autism and developmentally language-delayed children displayed enjoyment to music, the children with auitism seemed to indulge to a greater extend in the music, usually listened to the same song repeatedly. Additionally, we also found that both auditory hyposensitivity and hypersensitivity co-occured in one child with autism. The pathogenesis of the unusual phenomenon has not been yet known, though several potential hypotheses existed. Investigations have focussed on the distinctions between global and local processing in the central nervous system in autism [24]. Researchers reported that children with autism showed no enhancement over their non-autistic peers in global processing skills, but outformed their peers in local processing abilities. Another study interpreted the phenomenon as impaired global processing rather than enhanced local processing [25].

\subsection{Phonophobia}

Children with autism felt more discomfort when exposed to certain sounds. Moreover, regarding the relationship between auditory abnormalities and severity of presented autism, we observed a significant difference only in the domain of phonophobia, particularly the items of "overdistressed by some high-pitch voice" and "discomfort with usual sound of talking”. Severely autistic children also often showed more discomfort than the mild ones when exposed to the ordinary sounds putting their hands on the ears to cover them or losing their temper when exposed to the ordinary environmental sounds, whilst only a few more mildly affected children did. It is plausible that a subgroup of children who presented higher frequencies of phonophobia might have more trouble with the performance of daily living activities [11,26,27]. Studies indicated that the phonophobia may result from the stimulation of the autonomic nervous system and the triggering of protective reflexes [28].

\subsection{Peculiar Interests in Certain Sounds}

We observed that many participants with autism liked to 
make sounds and were fascinated with these sounds. They usually produced sounds by shaking a small bottle or knocking the table, while no children with language delay was observed to show this behaviour. Some children with autism also displayed unusual acuity of hearing of some television program (e.g. weather forecast or news broadcast).

Children with autism presented with varied auditory abnormalities which may be specific features in autism and may play an important role in the early identification of autism. This was a cross-sectional study, whereas longitudinal study would provide more clues to the developmental course of auditory responses in autism. In addition, it may be worthwhile studying the association between auditory abnormalities and other impairments, such as joint attention skills and stereotyped behaviors. Further studies (e.g. functional magnetic resonance imaging, magnetoencephalography) are needed to clarify the possible mechanism of the abnormalities.

\section{ACKNOWLEDGEMENTS}

This study was supported by the National Natural Science Foundation of China (Grant number: 30872802) and Educational Foundation of Liaoning Province (Grant number: 2008816). We are grateful to the children and their families for participating in the study.

\section{REFERENCES}

[1] American Psychiatric Association. (2000) Diagnostic and Statistical Manual of Mental Disorders, 4th Edition, Text Revision (DSM-IV-TR), Washington DC.

[2] World Health Organization. (1993) Mental disorders: A glossary and guide to their classification in accordance with the 10th revision of the international classification of diseases-research diagnostic criteria (ICD-10), Geneva, WHO.

[3] Fombonne, E. (2003) Epidemiological surveys of autism and other pervasive developmental disorders: An update. Journal of Autism and Developmental Disorders, 33, 365-382. doi:10.1023/A:1024419831376

[4] Kellerman, G.R., Fan, J. and Gorman, J.M. (2005) Auditory abnormalities in autism: Toward functional distinctions among findings. CNS Spectrums, 10, 748-756.

[5] Rogers S.J., Hepburn, S. and Wehner, E. (2003) Parent reports of sensory symptoms in toddlers with autism and those with other developmental disorders. Journal of Autism and Developmental Disorders, 33, 631-642. doi:10.1023/B:JADD.0000006000.38991.a7

[6] Wiggins, L.D., Robins, D.L., Bakeman, R. and Adamson, L.B. (2009) Brief report: Sensory abnormalities as distinguishing symptoms of autism spectrum disorders in young children. Journal of Autism and Developmental Disorders, 39, 1087-1091. doi:10.1007/s10803-009-0711-X

[7] Ben-Sasson, A., Hen, L., Fluss, R., Cermak, S.A., Engel-
Yeger, B. and Gal, E. (2009) A meta-analysis of sensory modulation symptoms in individuals with autism spectrum disorders. Journal of Autism and Developmental Disorders, 39, 1-11. doi:10.1007/s10803-008-0593-3

[8] Hitoglou, M., Ververi, A., Antoniadis, A. and Zafeiriou, D.I. (2010) Childhood autism and auditory system abnormalities. Pediatric Neurology, 42, 309-314. doi:10.1016/j.pediatrneurol.2009.10.009

[9] Dunn, W. (1999) The short sensory profile. The Psychological Corporation, San Antonio, TX.

[10] Gravel, J.S., Dunn, M., Lee, W.W. and Ellis, M.A. (2006) Peripheral audition of children on the autistic spectrum. Ear and Hearing, 27, 299-312. doi:10.1097/01.aud.0000215979.65645.22

[11] Harrison, J. and Hare, D.J. (2004) Brief report: Assessment of sensory abnormalities in people with autistic spectrum disorders. Journal of Autism and Developmental Disorders, 34, 727-730. doi:10.1007/s10803-004-5293-z

[12] Klintwall, L., Holm, A., Eriksson, M., Carlsson, L.H., Olsson, M.B., Hedvall, A., Gillberg, C. and Fernell, E. (2011) Sensory abnormalities in autism. A brief report. Research in Developmental Disabilities, 32, 795-800. doi:10.1016/j.ridd.2010.10.021

[13] Kwakye, L.D., Foss-Feig, J.H., Cascio, C.J., Stone, W.L. and Wallace, M.T. (2011) Altered auditory and multisensory temporal processing in autism spectrum disorders. Frontiers in Integrative Neuroscience, 4, 129. doi:10.3389/fnint.2010.00129

[14] Rosenhall, U., Nordin, V., Sandström, M., Ahlsén, G. and Gillberg, C. (1999) Autism and hearing loss. Journal of Autism and Developmental Disorders, 29, 349-357. doi:10.1023/A:1023022709710

[15] Seri, S., Pisani, F., Thai, J.N. and Cerquiglini, A. (2007) Pre-attentive auditory sensory processing in autistic spectrum disorder. Are electromagnetic measurements telling us a coherent story? International Journal of Psychophysiology, 63, 159-163. doi:10.1016/j.ijpsycho.2006.03.013

[16] Rosenhall, U., Nordin, V., Brantberg, K. and Gillberg, C. (2003) Autism and auditory brain stem responses. Ear and Hearing, 24, 206-214. doi:10.1097/01.AUD.0000069326.11466.7E

[17] Kwon, S., Kim, J., Choe, B.H., Ko, C. and Park, S. (2007) Electrophysiologic assessment of central auditory processing by auditory brainstem responses in children with autism spectrum disorders. Journal of Korean Medical Science, 22, 656-659. doi:10.3346/jkms.2007.22.4.656

[18] Tharpe, A.M., Bess, F.H., Sladen, D.P., Schissel, H., Couch, S. and Schery. T. (2006) Auditory characteristics of children with autism. Ear and Hearing, 27, 430-441. doi:10.1097/01.aud.0000224981.60575.d8

[19] Tecchio, F., Benassi, F., Zappasodi, F., Gialloreti, L.E., Palermo, M., Seri, S. and Rossini, P.M. (2003) Auditory sensory processing in autism: A magnetoencephalographic study. Biological Psychiatry, 54, 647-654. doi:10.1016/S0006-3223(03)00295-6 
[20] Oram Cardy, J.E., Flagg, E.J., Roberts, W. and Roberts, T.P. (2005) Delayed mismatch field for speech and nonspeech sounds in children with autism. NeuroReport, 16, 521-525. doi:10.1097/00001756-200504040-00021

[21] Gomes, E., Rotta, N.T., Pedroso, F.S., Sleifer, P. and Danesi, M.C. (2004) Auditory hypersensitivity in children and teenagers with autistic spectrum disorder. $A r$ quivos de Neuro-Psiquiatria, 62, 797-801. doi:10.1590/S0004-282X2004000500011

[22] Schopler, E., Reichler, R.J. and Renner B.R. (1988) The Childhood Autism Rating Scale (CARS). Western Psychological Services, Los Angeles, CA.

[23] Leekam, S.R., Nieto, C., Libby, S.J., Wing, L. and Gould, J. (2007) Describing the sensory abnormalities of children and adults with autism. Journal of Autism and Developmental Disorders, 37, 894-910. doi:10.1007/s10803-006-0218-7

[24] Mottron, L., Peretz, I. and Ménard, E. (2000) Local and global processing of music in high-functioning persons with autism: Beyond central coherence? Journal of Child Psychology and Psychiatry, 41, 1057-1065. doi:10.1111/1469-7610.00693

[25] Frith, U., and Happé F. (1994) Autism: Beyond "theory of mind”. Cognition, 50, 115-132. doi:10.1016/0010-0277(94)90024-8

[26] Pfeiffer, B., Kinnealey, M., Reed, C. and Herzberg, G. (2005) Sensory modulation and affective disorders in children and adolescents with Asperger's disorder. American Journal of Occupational Therapy, 59, 335-345. doi:10.5014/ajot.59.3.335

[27] Baranek, G.T. (2002) Efficacy of sensory and motor interventions for children with autism. Journal of Autism and Developmental Disorders, 32, 397-422. doi:10.1023/A:1020541906063

[28] O’Neill, M. and Jones, R.S. (1997) Sensory-perceptual abnormalities in autism: A case for more research? Journal of Autism and Developmental Disorders, 27, 283-293. doi:10.1023/A:1025850431170 